\title{
Ruptura, superação e engajamento no Ensino de Ciências
}

\author{
Tássia Alexandre Teixeira Bertoldo
}

Edson José Wartha

\section{Resumo}

Considerando a necessidade de reformas no ensino de Ciências e que a escola ainda não é uma instituição totalmente sintonizada com a realidade da produção do conhecimento, neste estudo buscamos apresentar e discutir um processo de ruptura, de superação e de ativismo no Ensino de Ciências. Para tanto, apresentamos nosso relato de experiência, de um lado professora de Ciências e de outro formador de professores de Ciências, que foi se constituindo em uma relação dialógica durante a pesquisa na sala de aula e reflexão sobre os resultados da pesquisa. Desse modo, verificamos que a ruptura é um processo doloroso, que a superação é necessária e, principalmente, o engajamento em uma nova proposta de ensino de Ciências, mais comprometido com uma formação crítica e cidadã nos levou a um ativismo com e para o Ensino de Ciências.

Palavras-chave: Prática docente; Conflitos; Reflexão; Engajamento. 


\section{Rupture, overcoming and engaging in science education}

Tássia Alexandre Teixeira Bertoldo

Edson José Wartha

\section{Abstract}

Considering the need for reforms in science teaching and that the school is not yet an institution fully attuned to the reality of knowledge production, in this study we seek to present and discuss a process of rupture, overcoming and activism in Science Teaching. To do so, we present our experience report, on the one hand science teacher and another teacher educator, which was becoming a dialogic relationship during the classroom research and reflection on the results of the research. In this way, we find that rupture is a painful process, that overcoming is necessary and, mainly, the engagement in a new proposal of science education, more committed to a critical and citizen formation has led us to an activism with and for Teaching of Sciences.

Keywords: Teaching practice; Conflicts; Reflection; Engagement 


\section{Introdução}

Falar em reformas no Ensino de Ciências sem fortalecer a escola é iniciar uma nova reforma já sabendo, de antemão, que será apenas mais uma fadada ao fracasso. Como espaço primordial de transformações, de contradições, de avanços e retrocessos, a escola, sem dúvida, é o espaço mais adequado e organizado para a aprendizagem em ciência e tecnologia. Contudo, sem oferecer aos docentes de Ciências um plano sistêmico de formação em serviço, com atividades de reflexão permanente, troca de experiências sobre a prática pedagógica, sem promover o trabalho conjunto da equipe escolar, favorecendo a construção coletiva do conhecimento científico sobre sua própria realidade, como é possível o sucesso escolar?

Rays (2000, p. 14) mostra que "a ação pedagógica escolarizada, quando consciente, não poderá, pois, distanciar-se da intenção política do tipo de ser humano que a educação pretende promover, para que não incorra na arbitrariedade pedagógica e política do ato educativo". Enfatiza que a dimensão política da ação educativa está presente mesmo antes do professor proferir sua aula, pois se apresenta desde o momento do planejamento, na elaboração dos objetivos, na seleção dos conteúdos, na escolha metodológica e nos processos de avaliação. Desta forma, não há como dissociar a ação pedagógica da intencionalidade, uma vez que ela está presente em cada etapa deste processo pedagógico.

A percepção crítica das diferentes realidades que estão associadas ao ato de ensinar, a percepção sobre a necessidade de mudança e a percepção sobre o atual ensino torna-se fundamental para que o educador, consciente de suas responsabilidades e de sua importância no processo, planeje sua ação pedagógica no sentido não de que o estudante aprenda conceitos científicos, mas sim usar os conceitos para tomar decisões de vida. Então, ensinar Ciências para quê? Para quem? E, por que ensinar Ciências.

Estas e outras inquietações foram me levando de volta a universidade. Lá, o encontro com os outros colegas professores com inquietações semelhantes, o confronto dos textos teóricos com a realidade vivida, muitas vezes não percebida dentro da sala de aula, foram suficientes para me causar "espanto". Lembro-me bem como esse processo começou. Era a sétima aula da disciplina que eu chamava de "Saberes" do Mestrado em Ensino de Ciências e Matemática da Universidade Federal de Sergipe. Muito cansada e sonolenta, pois havia passado a noite em claro lendo e refletindo sobre a leitura recomendada para a aula (A Formação do Espírito Científico, de Gaston Bachelard), abri a porta e entrei silenciosamente.

Na sala de aula, que sempre estava arrumada de forma circular, havia algumas cadeiras vazias, sentei em uma delas, abri meu texto e comecei a ouvir as discussões que iniciara as nove horas. Sempre muito participante, desta vez eu estava calada. O texto para aquela aula havia causado uma série de inquietações que me fizeram entrar em um conflito interno com minhas convicções enquanto professora de Ciências, e olha que eu era considerada uma ótima 
professora nas escolas onde atuava e continuo atuando. Eu perguntava para mim mesma: que tipo de professora eu sou? Eu mato o espírito científico dos meus alunos? O que foi que eu fiz nesses dez anos de sala de aula?

Com o pensamento voltado em refletir sobre estas e outras questões, ouvi o professor da disciplina, ao longe dizendo: Tássia, chegou tão quieta. Queremos ouvir você. O que você tem a nos dizer sobre ess a primeira parte do texto? Ao olhar para os colegas e para o professor, não conseguia responder nada, só chorava. Senti uma mão leve em minhas costas dizendo: Calma Tássia, o que houve? Eu enxuguei as lágrimas, pedi desculpas e ainda com a voz embargada, comecei a falar o que sentia naquele momento. Expliquei que o texto havia me deixado pensativa, pois estava completando naquela semana dez anos de sala de aula e me perguntava que tipo de professora eu havia sido até aquele dia. Nunca um texto tinha mexido tão profundamente com minhas convicções enquanto professora como aquele texto de Gaston Bachelard.

O texto se apresentava mais ou menos assim: o professor tem que conduzir o aluno para a atividade racional, controlando os obstáculos que se opõem ao conhecimento objetivo, ao conhecimento tranquilo. Infelizmente os educadores não colaboram para essa tranquilidade! Não conduzem os alunos para o conhecimento do objeto. Emitem mais juízos do que ensinam! (BACHELARD, 1996, p. 258). Bachelard também expõe seu depoimento como professor:

pouco a pouco, procuro liberar suavemente o espírito dos alunos de seu apego a imagens privilegiadas. Eu os encaminho para as vias da abstração, esforçando-me para despertar o gosto pela abstração. Enfim, acho que o primeiro princípio da educação científica é, no reino intelectual, esse ascetismo que é o pensamento abstrato. Só ele pode levar-nos a dominar o conhecimento experimental. (BACHELARD, 1996, p. 292).

Mas, talvez o que mais tenha me marcado foi ouvir que os professores de ciências imaginam que o espírito científico começa com uma aula, que é sempre possível reconstruir uma cultura falha pela repetição da lição, que se pode fazer entender uma demonstração repetindo-a ponto por ponto. Não levam em conta que o estudante entra na sala de aula com conhecimentos empíricos já constituídos.

Quanto mais "ouvia" o texto, mais eu me via fazendo exatamente isso com meus estudantes. Comecei a entrar em prantos, pois eu percebi que em minhas aulas eu estava matando o espírito científico. Penso que neste momento se deu início a uma "catarse intelectual e afetiva" pois, vi que era necessário me apropriar de novos campos conceituais no Ensino de Ciências e de outro lado, também não poderia deixar toda minha experiência adquirida em 10 anos de sala de aula para trás. Devia ter algo que pudesse aproveitar (afetividade). Não poderia deixar de acreditar em meu potencial, afinal eu sempre fui 
considerada pelos meus alunos, uma ótima professora. Afinal eu sou ou era apaixonada pelo meu trabalho.

Tentando me reconstruir após esse Tsunami que me encontrou em seu caminho. Bem, passado o susto, passei a tentar compreender o que estava acontecendo comigo, como sair destes destroços e buscar uma saída. A princípio, uma das saídas foi estar em um grupo de pesquisa que aborda a questão da formação de professores, na perspectiva da reflexão orientada, de modo que foi possível pensar novas estratégias de ensino, de avaliar estas estratégias e de refletir sobre tudo isso tem colaborado significativamente neste processo que denominaremos de ruptura docente. Ruptura no sentido Kunhiano da palavra, ou melhor, metáfora da revolução da prática docente. Thomas Khun (2000) nos coloca que as revoluções do pensamento são definidas como um momento de desintegração da visão tradicional numa disciplina, forçando a comunidade de profissionais que nela trabalham a reformular o conjunto de compromissos (paradigma) em que se baseia a prática dessa ciência.

A partir das revoluções surgem novas formas de ver o mundo, de explicar o novo e de olhar para o passado. Assim, na perspectiva kuhniana, para que se dê essa revolução científica, a primeira exigência é o aparecimento de um novo paradigma, isso porque "uma vez encontrado um primeiro paradigma com o qual conceber a natureza, já não se pode mais falar em pesquisa sem qualquer paradigma. Rejeitar um paradigma sem simultaneamente substituílo por outro é rejeitar a própria ciência” (KUHN, 2000, p. 110).

Assim, semelhante as revoluções científicas, fui desafiada a fazer minha própria revolução. Percebi que tanto a ruptura com as velhas práticas quanto a superação só seriam possíveis, se de fato houvesse um engajamento de minha parte que viesse de dentro para fora, que não seria fácil, mas necessária. Pode parecer estranho, mas todas minhas inquietações, descobertas, frases de texto que faziam sentido eu anotava em meu caderno que denominava de "diário de bordo".

Para mim, este bloco de anotações foi extremamente importante durante o processo de ruptura, pois nele ficavam registradas as principais ideias que me faziam refletir. Eram ideias que iam desde relatos acerca da minha prática docente até ideias relacionadas a minha visão de mundo que muitas vezes eram contraditórias às ideias que vinham dos textos que estávamos discutindo na disciplina do mestrado, bem como de minhas reflexões enquanto estava ministrando aulas com meus alunos da sexta série do Ensino Fundamental.

Dessas anotações e, principalmente das reflexões que fazia sobre elas é que fui me engajando em um processo de superação de velhas práticas na construção de uma nova professora, não com uma nova visão de mundo, mas com uma ampliação do campo de visão, o que me permitiu vislumbrar outras estratégias de atuação em sala de aula sem perder as minhas características enquanto pessoa. Características que estão sendo moldadas, ISSN 2526-2882 
transformadas há mais de três décadas e que representam um ser histórico e social que estou neste momento. Momento de crises, conflitos e de muitas dúvidas em momento em que estamos atravessando uma crise, também, de identificação profissional com ampla repercussão em seu status e com consequências também, no próprio contexto social, além do pessoal.

Como diz Nóvoa (1996), “a identidade é um lugar de lutas e de conflitos, é um espaço em construção de maneiras de ser e de estar na profissão. Por isso, é mais adequado falar em processo identitário, realçando a mesma dinâmica que caracteriza a maneira como cada um se sente e se diz professor”. Crise de identidade do professor significa, portanto, uma crise da maneira de ser na profissão, isto é, uma crise no ato de professar e que implica em dificuldades na interação social; descontentamento na realização das suas atividades, descrença no seu papel social, por exemplo.

Posso afirmar que é extremamente difícil desmembrar um modo de ser pessoal crenças, valores morais, posturas ou aspectos do caráter - de tudo aquilo que compõem o modo de ser professor - crenças a respeito da educação, valores pedagógicos, posturas didáticas e estratégias de ensino adotadas. Como nos coloca Mesknas (2004), não é possível que "jogue fora as suas crenças" e que "liberte-se da especificidade do seu caráter" quando realiza as suas atividades docentes. Trata-se de pensar sobre como determinados modos de ser pessoal relacionam-se ao exercício da profissão docente.

\section{Superação: pensamento crítico e rodas de conversa}

No meio de todo este processo de angústia, inquietações e até mesmo de desespero, me deparei nas reuniões do grupo de pesquisa, com o referencial teórico do Pensamento Crítico. Tenreiro-Vieira e Vieira (2000), afirmam que "o uso das capacidades do pensamento crítico permite aos indivíduos tomarem posições sobre as questões científicas, raciocinando logicamente sobre o tópico em causa, de modo a detectar incongruências na argumentação ou no sentido de suspender a tomada de decisão no caso de parecer haver evidências insuficientes para traçar e sustentar uma conclusão". A promoção ou o ensino do Pensamento Crítico pode ser feito a partir de diferentes abordagens, tanto num aspecto de curso separado quanto na junção de diferentes disciplinas no currículo escolar. No primeiro a abordagem é feita dentro de uma única matéria, permitindo enfatizar inteiramente a concentração dos alunos nas capacidades do pensamento crítico que se objetiva desenvolver, e no outro a abordagem é feita entrelaçando as disciplinas, onde desenvolve-se a compreensão do conhecimento científico a partir do domínio do assunto, a forma contextualizada auxilia impactando no desenvolvimento do aluno nas disciplinas curriculares evitando a necessidade de uma disciplina extra no currículo. 
De acordo com Tenreiro-Vieira; Vieira (2005), o emprego dessas abordagens potencializam as possibilidades de aplicação das capacidades do pensamento crítico, pois viabilizam aos alunos usarem as capacidades numa diversidade de contextos, explorando a diferentes processos de comunicação e utilizando numerosas estratégias. Para esses autores, a aplicação de capacidades de pensamento crítico tem que ser ensinada, sob pena de não ser realizada pelos alunos. Entre as sugestões no ensino do pensamento crítico para a aplicação de capacidades incluem: (1) demonstrar o modo como as capacidades de pensamento crítico podem ser empregadas em diversas situações; (2) moldar o uso de capacidades de pensamento crítico; e (3) diversificar as situações ou atividades com base nas quais se propõe as capacidades de PC, tendo como importância o uso de situações da vida real.

A aplicação do pensamento crítico pode ocorrer a partir de vários princípios, de diferentes tipos, como ser receptivo às questões dos alunos, exigir clareza, envolver os alunos em discussões, encorajá-los a, gradativamente, deter o controle e a responsabilidade pela sua aprendizagem, a tomar consciência do que estão a fazer e a rever o que fizeram e, ainda, a fazer algo de maneira diferentes. Acredita-se que as práticas docentes, com a utilização de metodologias intencionais permitem ao professor construir atividades de aprendizagem ou materiais curriculares promotores de pensamento crítico. Bem, aqui já tinha encontrado o novo paradigma e, o que faltava, era construir uma nova estratégia de ensino que levasse em consideração minhas experiências exitosas e que me permitissem desenvolver nos estudantes, capacidades de pensamento crítico e por que não o "espírito científico".

Foi neste momento que pensei em minhas Rodas de Conversa. Elas faziam parte da minha prática docente, mas poderiam ser melhores aproveitadas e planejadas. A Roda de Conversa passou a ser entendida e utilizada como uma metodologia participativa em que se propõe partilhar experiências e desenvolver reflexões. Muito utilizada em intervenções comunitárias, seu referencial teórico parte da articulação de autores da psicologia social, da psicanálise, da saúde e da educação. Seu fundamento metodológico se baseia nas oficinas de intervenção psicossocial, tendo como principal objetivo a constituição de um espaço onde seus participantes ponderem acerca do cotidiano, considerando sua relação com o mundo, com o trabalho e com seus projetos de vida.

De acordo com Méllo et. al (2007), as Rodas de conversa priorizam discussões em torno de uma temática (selecionada de acordo com o contexto dos participantes) e, no processo dialógico, as pessoas podem apresentar suas elaborações, mesmo contraditórias, sendo que cada pessoa instiga a outra a falar, sendo possível se posicionar e ouvir o posicionamento do outro. As colocações de cada participante são construídas por meio da interação com o outro, seja para complementar, discordar, seja para concordar com a fala imediatamente anterior. 
Conversar, nesse sentido, significa compreender com mais profundidade, refletir mais e ponderar, no sentido de compartilhar, como assim partilha Warschauer (2001, p. 179):

Conversar não só desenvolve a capacidade de argumentação lógica, como, ao propor a presença física do outro, implica as capacidades relacionais, as emoções, o respeito, saber ouvir e falar, aguardar a vez, inserir-se na malha da conversa, enfrentar as diferenças, o esforço de colocar-se no ponto de vista do outro etc. $[\ldots]$.

Compreende-se que as Rodas de Conversa promovem a repercussão coletiva, a construção e a reconstrução de conceitos e de argumentos através da escuta e do diálogo com os outros e consigo mesmo. E, ao pensar a forma de adotar e conduzir esse instrumento, temos que considerar que o diálogo construído representa o pensar e o falar de "indivíduos com histórias de vida diferentes e maneiras próprias de pensar e de sentir, de modo que os diálogos, nascidos desse encontro, não obedecem a uma mesma lógica” (WARSCHAUER, 2002, p. 46).

As Rodas de Conversa que também estavam presentes no processo de reflexão orientada no grupo de pesquisa me fizeram refletir sobre um termo, que até o presente momento nunca tinha parado para pensar, o “Tempo de Resposta”. Pode soar estranho, mas no processo de elaboração conceitual que ocorre ao longo de uma discussão sobre determinado tema ou conceito, a questão do “Tempo de Resposta” foi o que mais me deixou impressionada. Ao analisar e refletir sobre os dados da primeira roda de conversa que realizei com os estudantes do sexto ano, pude verificar que eu fazia muitas perguntas e, na maioria das vezes eu mesma respondia, não porque eles não pudessem ou não soubessem responder, mas porque eu não dava o tempo necessário para que os estudantes refletissem, elaborassem qualquer argumento e processassem uma possível resposta ou indagação.

Depois desta reflexão, quando eu fazia um questionamento na Roda de Conversa eu contava nos dedos o tempo (o5 ou 10 segundos) antes de fazer outra intervenção e, para minha surpresa o resultado foi surpreendente, tanto na participação quanto na qualidade das respostas. Simples, aumentando o tempo de resposta é possível um aumento significativo nas interações discursivas em sala de aula.

O questionamento em sala de aula é fundamental para produzir boas interações verbais sobre determinados temas em sala de aula e, ao mesmo tempo, permitir que os estudantes sejam desafiados a pensar e a manifestar capacidades de pensamento crítico, ou seja, pode ativar processos metacognitivos fundamentais no processo de aprendizagem. Porém, é interessante levar em consideração que há diferentes tipos e níveis de questões.

Jesus (1987) realizou um estudo em que selecionou dois aspectos particulares de questionamento: o tipo de questões e o tempo de espera utilizado pelos professores. Os resultados deste estudo mostraram que $75 \%$ das questões dos professores são fechadas, isto é, ISSN 2526-2882 
questões de rotina e questões para lembrar de fatos com baixo nível cognitivo. Verificaram que questões de alto nível cognitivo, questões de pensamento divergente e de pensamento avaliativo não passam de $5 \%$ das questões. Mas, o que mais nos chamou atenção neste estudo foi o tempo de espera. Foi um tanto quanto assustador para mim aceitar que uma pequena pausa após uma questão pode resultar em resultados impressionantes sobre a qualidade das repostas dos estudantes.

Em relação ao tempo de espera, uma linha de investigação tem feito distinção entre o tempo de espera 1 e o tempo de espera 2. O tempo de espera 1 refere-se ao que o professor concebe para a resposta do aluno antes de repetir, refazer ou fazer outra questão diferente ou então direcionar a questão para outro aluno. Depois do aluno deixar de falar, o tempo de espera para o professor reagir ou formular outra questão é o tempo de espera 2 (TENREIRO-VIEIRA; VIEIRA, 2005). A maioria dos professores e eu principalmente, independentemente do nível ou do tema que se esteja abordando, quer no tempo de espera 1 ou tempo de espera 2 , fazemos pausas de 1 segundo ou menos.

Bem, após calcular o tempo de espera 1 em minhas aulas, ou seja, nas rodas de conversa, pude observar que não passava de 1 segundo. Ao aumentar o tempo de espera para 5 segundos fiquei assustada com a diferença e na qualidade das respostas. Ao verificar o resultado de outros estudos que apontam no sentido do aumento do tempo de espera 1 e 2 são conseguidas melhoras significativas em diferentes níveis no processo de ensino e aprendizagem de ciências. Mas, o que mais me chamou atenção e que também pude constatar em minhas aulas é que ao aumentar o tempo de espera, seja o tempo 1 ou 2, os alunos também começam a fazer questões e suas repostas são mais longas e mais elaboradas.

Outro aspecto que me deixou intrigada e me faz refletir até hoje foi quando, durante um seminário ouvi a expressão "problemas que não são problemas”. Muitas das vezes aquilo que pensamos ser bons problemas para criar situações problemas e levar para a sala de aula como forma de provocar discussões e reflexões, podem não ser problemas para os estudantes. Confesso que novamente tive a impressão de que um novo Tsunami vinha para cima de mim, dado o estrago que estava causando novamente sobre minha prática. O caso do problema que não é problema me fez pensar que na Rodas de Conversa fui eu que apresentei todos os problemas, mas e agora? Será que eram problemas para meus alunos? Será que novamente estarei "matando o espírito científico dos alunos?"

Vamos tentar colocar o que compreendemos sobre o caso de problemas que não são problemas. Falas descontextualizadas, ou seja, sem levar em consideração aspectos socioculturais dos estudantes podem se configurar em problemas que não são problemas, se os docentes também não fazem parte desse contexto sociocultural. A partir dessa ideia é possível compreender porque na educação escolar indígena é quase que imprescindível que os ISSN 2526-2882 
professores também sejam indígenas ou que em uma escola quilombola os professores também façam parte do contexto sociocultural quilombola.

É necessário compreender que os fenômenos da natureza, explicando-os pelo entorno, pela realidade local, seria muito mais frutífero, ou seja, fazer o estudante pensar e falar sobre questões relacionadas ao seu contexto sociocultural permite um engajamento maior do estudante perante o tema que está sendo abordado. Não queremos dizer com isso que os conhecimentos a serem ensinados devam ser somente aqueles aos quais os estudantes estão próximos ou têm e/ou podem visualizar, mas colocar que todo conhecimento deva ter uma relação com o contexto. Afinal todo conhecimento é construído sobre algo do mundo material.

Como afirma Cassiani (2018, p. 236), "entendemos que a proposição de conhecimentos mais focados aos problemas poderia melhor contribuir para o país, no sentido de que pudessem refletir e tentar resolver seus próprios problemas, e não problemas importados de sociedades ocidentalizadas. Porém, nem sempre o que pensamos ser um problema, o é. Na verdade, pode ser um não-problema, e isso também precisa ser trabalhado na formação de professores".

Reconhecendo que a problematização é importante para o Ensino de Ciências, mas é necessário reconhecer que a maioria dos problemas apresentados no livros didáticos ou apresentados nas sequências de ensino, muitos deles não são problemas reais para os estudantes, mas sim perguntas apenas na busca de definições visto que são problemas que não apresentam relação com o contexto sociocultural em que estes estudantes estão inseridos ou esta relação fica apenas no aspecto da exemplificação sem que se estabeleçam relações mais amplas.

O engajamento que buscamos é no sentido da superação de práticas cristalizadas no fazer docente. Algumas mudanças se fazem necessárias, outros nos são impostas pelo sistema de ensino e outras pela própria realidade da nossa escola. Reconhecemos que qualquer processo de mudança é trabalhoso, assusta, não sabemos qual direção tomar e nos sentimos inseguros. Há um certo consenso na sociedade de que a escola deve mudar e espera-se essa mudança principalmente no foco de atuação do professor. Pode-se dizer que nunca foi tão difícil como ser professor atualmente. Como afirma Hagemeyer (2004, p. 72):

Para dimensionar esse processo, evocamos o conceito marxista de trabalho, no qual o homem, ao agir e transformar o objeto sobre o qual atua, o transforma, transformando-se a si mesmo. Karl Marx caracteriza esse processo como práxis, processo em que o pensamento humano adquire verdade objetiva, a partir não da teoria, mas da prática. A práxis se expressa no trabalho pedagógico como ação, reflexão e transformação do sujeito que dele participa, considerando a natureza não material da educação escolar, isto é, a produção de ideias, símbolos, hábitos, atitudes e habilidades. 
Falar em engajamento, é para nós, falar de agir, transformar o objeto de ensino e ao mesmo tempo sendo transformado por ele. Assim, vimos o engajamento como um processo de ação, reflexão e transformação. Ao observar minhas próprias práticas, diante das leituras de teóricos que discutem questões relacionadas a aspectos pedagógicos e metodológicos sobre o Ensino de Ciências, foi possível verificar que, em sua maioria, eles objetivavam ações e resolução de problemas pontuais, muitas vezes um não-problema para os estudantes, pelo fato de não considerar um processo de enfretamento sócio-histórico e intencionalmente politizado.

Gramsci (1995, p. 132) afirmou que se o corpo docente é relaxado, visando a resolver a questão do ensino com esquemas de papel no qual se exalta a educatividade, a obra do professor se tornará deficiente, tendo-se assim uma escola retórica em que o verdadeiro será verdadeiro de palavras.

É nesse contexto que a filosofia da práxis educativa propõe repensar a prática e a teoria considerando-as uma unidade que coloca, para além da sala de aula, o compromisso político do professor com a transformação das relações sociais. Esse compromisso dos professores e professoras é fundamental para elaboração de uma leitura crítica acerca do cotidiano escolar. Entretanto, para que se faça essa leitura é preciso refletir sobre seu papel diante da sociedade assumindo um compromisso não apenas em si (em nível de discurso), mas para si, ou seja, para ele mesmo enquanto sujeito do processo histórico, exercitando-o em sua própria prática.

Para isso, o professor precisa conhecer de forma clara (a) quem deve ser ensinado, (b) o que deve ser ensinado, (c) com que finalidade isso deve ser ensinado, (d) quanto deve ser ensinado e (e) como deve ser ensinado. Talvez, o mais importante seja a própria reflexão sobre os resultados de todo este processo. Reflexão para avaliar as práticas, as estratégias utilizadas, o engajamento dos estudantes, a construção de argumentos, os resultados alcançados na perspectiva de avaliar o que pode ser alterado, modificado de forma a serem mais efetivos no processo de elaboração conceitual, bem como na tomada de decisões.

\section{Considerações quase finais}

Como colocado no próprio título deste artigo, a questão da ruptura, da superação e do engajamento no Ensino de Ciências são processos que demandam escolhas, que demandam mudanças, que demandam comprometimento, que demandam reflexão, que demandam estudos, que demandam...demandam. Às vezes, parece que é melhor e mais cômodo ficar inerte, apenas cumprir e seguir os manuais escolares ou, as vezes, dá vontade de desistir e ir procurar outra profissão, e às vezes dá vontade de chorar e outras vezes eu me vejo fazendo tudo ao contrário e vou mergulhando nas minhas angústias, nos meus conflitos pessoais e profissionais e penso na necessidade de uma ruptura kunhiana na minha prática docente, ou

ISSN 2526-2882 
seja, repensar qual é o meu papel enquanto professora de Ciências, enquanto educadora e formadora de opinião e de projetos de vida para estes estudantes que passam pelas minhas mãos. Qual de fato é minha responsabilidade e importância na vida ou nas escolhas de vida destes estudantes?

Penso que a falta de reflexão sobre a própria prática resulta em aulas com transmissão de informações que podem até gerar mudanças, porém pontuais e sem grandes efeitos para instrumentalização de práticas sociais mais críticas dos sujeitos. Penso também, que só a reflexão não é suficiente, é necessária uma ruptura com práticas docentes cristalizadas com muita ênfase nos conceitos e propor mais ênfase nas práticas, sociais, no desenvolvimento de capacidades de pensamento crítico e de competências socioemocionais, de modo a contribuir na formação de um sujeito mais humano enquanto sujeito de sua própria história e que este seja capaz de se posicionar criticamente frente às demandas sociais, tecnológicas e ambientais.

O desafio que se coloca aqui é de que os educadores que compartilham dessa perspectiva formulem e reformulem suas práticas pela práxis afim de criar condições para uma ruptura com relações sociais hegemônicas e opressoras. É preciso romper com a "ordem e a disciplina” para pensar novas práticas pedagógicas no Ensino de Ciências. É preciso “ensinar" os estudantes a subirem nas cadeiras escolares todos os dias (ruptura com certos padrões escolares), o que nos leva a refletir sobre o tipo de escola e educação que defendemos. Uma das características fundamentais do papel social da escola, na perspectiva que defendemos é ser um ambiente de socialização do conhecimento historicamente produzido e sistematizado, ou seja, o saber elaborado (ciência), enquanto elemento de ligação com e para a prática social. O que compreende o processo de socialização, assimilação e reelaboração do saber de forma ativa, tendo em vista que a sua proposição pedagógica visa aproximar a ligação entre os conteúdos e as realidades e práticas sociais dos educandos.

Dentro deste contexto, o Ensino de Ciências deve levar em consideração algumas questões importantes para o início de uma ruptura (pedagógica), como: o ensino contextualizado e problematizado com as demais áreas do conhecimento, tendo em vista, que a Ciência não se compreende por si só, mas a partir dos contextos sociais, culturais, políticos, filosóficos, sexuais, religiosos e econômicos. Também é necessário a superação (velhas práticas) com a clareza do que se quer e onde se quer chegar. A superação exige comprometimento, estudo, reconstrução e, acima de tudo, engajamento.

E, para não finalizar, mas apenas ir colocando os pontos finais neste texto, gostaria de compartilhar com outros professores que o engajamento no sentido e um compromisso moral e ético com os estudantes, com seus pares, com a comunidade escolar e os diversos atores do sistema educacional é uma das possibilidades que vejo na busca constante da melhoria da prática, do sentido do trabalho e do reconhecimento da sua importância tanto para mim como 
para toda a comunidade escolar. Ao passar e enfrentar todos estes conflitos, angústias e enfrentar dois Tsunamis ainda estou na luta, comprometida e reconstruindo, não só, mas com outros colegas e pesquisadores. Sei também, que este processo pode ter tido um início, mas que não haverá um fim. Sei que sempre será necessário novas rupturas, novas superações e novos engajamentos.

\section{Referências}

CASSIANI, S. Reflexões sobre os efeitos da transnacionalização de currículos e da colonialidade do saber/poder em cooperações internacionais: foco na educação em ciências. Ciênc. Educ., Bauru, v. 24, n. 1, p. 225-244, 2018. doi:https://doi.org/10.1590/1516-731320180010015

GRAMSCI, A. Os intelectuais e a organização da cultura. Tradução de Carlos Nelson Coutinho, 9 ed. Rio de Janeiro: Civilização Brasileira, p. 252, 1995.

HAGEMEYER, R. C. Dilemas e desafios da função docente na sociedade atual: os sentidos da mudança. Educar, Curitiba, n. 24, p. 67-85, 2004.

JESUS, M. H. A descriptive study of some science teachers questioning practices. Publishedmasterthesis. Norwich: EastAngliaUniversity, 1987.

KUHN, T. A estrutura das revoluções científicas. $3 \cdot{ }^{a}$ edição. São Paulo: Perspectiva, 2000.

MÉLlO, R. P.; SILVA, A. A.; LIMA, M. L. C. Construcionismo, práticas discursivas e possibilidades de pesquisa em psicologia social. Psicologia \& Sociedade 19(3), 2007. doi: https://doi.org/10.1590/S0102-71822007000300005

MESKENAS, P. O Lugar da Ética no trabalho do (a) professor(a). Revista Eletrônica Espaço Acadêmico, Maringá/PR, v. 1, p. 01-05, 2004.

NÓVOA, A. As ciências da educação e os processos de mudanças. In: PIMENTA. Selma Garrido. Pedagogia, ciência da educação? São Paulo, Cortez, 1996.

RAYS, O. A. Trabalho pedagógico: hipóteses de ação didática. Santa Maria: Palloti, 2000. TENREIRO-VIEIRA, M.C; VIEIRA, R. M. Estratégias de ensino/aprendizagem: o questionamento promotor do pensamento crítico. Lisboa: Editorial do Instituto Piaget, 2005.

WARSCHAUER, C. A roda e o registro: uma parceria entre professor, alunos e conhecimento. Paz e Terra, 2002.

WARSCHAUER, C. Rodas em rede: oportunidades formativas na escola e fora dela. Paz e Terra, 2001.

ISSN 2526-2882 


\section{Biografia Resumida}

Tássia Alexandre Teixeira Bertoldo: Graduada em Ciências Biológicas com Mestrado em Ensino de Ciências (2018) pelo Programa de Pós-Graduação em Ensino de Ciências e Matemática - PPGECIMA-UFS. Doutoranda em Educação pelo PPGED-UFS. É professora de Ciências e Biologia da rede estadual de ensino SEDUC/SE.

e-mail: tassiaalexandre@hotmail.com

Edson José Wartha: Graduado em Química, com Mestrado (2002) e Doutorado (2013) em Ensino de Ciências pela USP. É professor da Universidade Federal de Sergipe - UFS, no Departamento de Química e no Programa de Pós-Graduação em Ensino de Ciências e Matemática - PPGECIMA-UFS.

e-mail: ejwartha@pq.cnpq.br 